Original Research Article

\title{
A prospective observational study to evaluate potential drug-drug interactions in patients admitted in intensive care unit, at BRIMS tertiary care hospital in Bidar, India
}

\author{
Shailander Singh, Swetha K.*
}

Department of Pharmacology, Bidar Institute of Medical Sciences, Bidar, Karnataka, India

Received: 17 January 2018 Accepted: 28 February 2018

*Correspondence to:

Dr. Swetha K.,

Email: swethakotragowdappa @ gmail.com

Copyright: () the author(s), publisher and licensee Medip Academy. This is an openaccess article distributed under the terms of the Creative Commons Attribution NonCommercial License, which permits unrestricted noncommercial use, distribution, and reproduction in any medium, provided the original work is properly cited.

\begin{abstract}
Background: Drug interaction occurs when presence of one drug affects the activity of another when, both are co-administered. 6-30\% of adverse events (AEs) with significant hospitalizations or death are by drug-drug interactions(DDI). There is increased possibility to prevent the potential drugdrug interactions (pDDIs), if their prevalence and pattern are determined accurately before their occurrence. Hence this study aimed to evaluate the prevalence of pDDIs in ICU patients at BRIMS tertiary care hospital, Bidar.

Methods: This prospective observational study included 30 patients admitted in ICU of BRIMS hospital for $>24 \mathrm{hrs}$ of either gender, aged $>18$ yrs. The study was conducted for a period of 3 months. Data was collected from the case records of patients on the predesigned proforma. Potential drug-drug interactions were classified based on their severity and the risk of Potential drug-drug interactions was estimated by Lexicomp, inc.version; 3.0.1.drug interact android mobile application.
\end{abstract}

Results: Out of 35 patients admitted in the ICU, 30 cases were included in the study. The mean age of study population was 56.3 years. The study population was exposed to a total of 330 medicines during the hospital stay with an average of 11.7 drugs per patient. The prevalence of pDDI was $93.3 \%$ (28) with an average of $9.75 \mathrm{pDDI}$ per patient. According to Lexicomp drug interact android mobile application majority (63\%) of pDDI were found to be moderate in their severity, $67 \%$ belonged to type $\mathrm{C}$ risk.

Conclusions: The study showed higher prevalence of pDDI among ICU patients due to the complexity of the pharmacotherapies administered.

Keywords: Drug-drug interaction, ICU, Patient safety

\section{INTRODUCTION}

Drugs have beneficial therapeutic effects but they can also produce undesirable consequences. Drug-drug interactions (DDIs) are one such undesirable or a beneficial consequence of using two or more drugs simultaneously. DDI is a specific type of adverse event (AE) that occurs when there is an alteration in the effectiveness or toxicity of one drug due to presence of simultaneously administered another drug. This interaction leads to reduced, null or increased drug response. ${ }^{1,2}$ In most of the health care systems errors in practice are quiet common and these are reported to be the seventh most common cause of death overall. ${ }^{3}$ Evidence from epidemiologic studies shows that $6-30 \%$ of AEs with significant hospitalizations or death are caused by DDIs. ${ }^{4}$

Based on the mechanism by which drugs interact with each other, DDI can be classified as pharmacokinetic and pharmacodynamic. Risk factors for drug interactions can be related to patient, drug and medical prescription. Patient-related factors include people who are more vulnerable to drug interactions like the elderly with polytherapy, patients with hepatic or renal insufficiency, 
patients with more than one prescribing doctor, those receiving intensive care (ICU), and immunosuppressed patients. ${ }^{5}$ Polytherapy increases the risk of clinically relevant drug interactions. ${ }^{6,7}$

The development of drug-drug interactions is particularly common in ICU patients and this predisposition is complicated by disease severity and organ failure, both of which can change the pharmacologic response of medications. ${ }^{8,9}$ In ICU patient's pDDI go unnoticed, as the symptoms due to DDI are masked by their preexisting disease symptoms. DDI has become a significant challenge to health care providers and may affect morbidity, mortality and patient's quality of life. ${ }^{10}$

Hence it is crucial to monitor these patients closely and the health care professionals should be trained efficiently in this aspect. ${ }^{11}$ There is increased possibility to prevent the potential drug-drug interactions (pDDIs), if the prevalence and pattern of pDDI are determined accurately before their occurrence. ${ }^{12}$ Unfortunately, there are limited studies on the preventability of adverse events (AEs) due to pDDIs. Hence this present study was aimed to evaluate the prevalence of potential DDIs in the ICU patients admitted at BRIMS tertiary care hospital, Bidar.

\section{METHODS}

A prospective observational study was conducted to assess the prevalence of pDDIs and to determine drugs involved in potential DDIs in the ICU patients admitted at BRIMS tertiary care hospital, Bidar, India. The study was conducted for a period of 3 months after obtaining Institutional Ethics Committee approval. Patients were selected randomly who were aged 18 years or older admitted to the Intensive Care Unit from October 2016 to December 2016, who had a length of stay of $>24 \mathrm{hrs}$ and had more than two medicines in their treatment chart were included in the study. Data was collected from the case records of patients on the predesigned proforma, which included the following details;

- Demographic data.

- Provisional diagnosis.

- Prescription details: Number of drugs prescribed, drug class / category, dose, route, frequency and duration of administration.

- Length of stay in the hospital.

Potential drug-drug interactions were classified according to pharmacodynamics and pharmacokinetics properties and their severity and the risk of Potential drug-drug interactions will be estimated by Lexicomp, inc. version;3.0.1. drug interact android mobile application Table 1 and Table $2 .^{3}$

The data was analysed for pDDI by using drug interaction software Lexi- Comp, inc. version: 3.0.1.
The drug interactions that are not available in Lexi Comp Drug Interact were excluded from the study.

Table 1: DDI severity scale.

\begin{tabular}{|ll|}
\hline Category & Description \\
Major & $\begin{array}{l}\text { Effects may result in death, } \\
\text { hospitalization, permanent injury, or } \\
\text { therapeutic failure }\end{array}$ \\
\hline \multirow{3}{*}{ Moderate } & $\begin{array}{l}\text { Medical intervention needed to treat } \\
\text { effects; effects do not meet criteria for } \\
\text { major }\end{array}$ \\
\hline \multirow{2}{*}{ Minor } & $\begin{array}{l}\text { Effects would be considered tolerable in } \\
\text { most cases; no need for medical } \\
\text { intervention }\end{array}$ \\
\hline
\end{tabular}

Table 2: DDI risk rating.

\begin{tabular}{|c|c|c|}
\hline $\begin{array}{l}\text { Risk } \\
\text { rating }\end{array}$ & Action & Description \\
\hline A & $\begin{array}{l}\text { No known } \\
\text { interaction }\end{array}$ & $\begin{array}{l}\text { Data have not demonstrated } \\
\text { either pharmacodynamic or } \\
\text { pharmacokinetic interactions }\end{array}$ \\
\hline B & $\begin{array}{l}\text { No action } \\
\text { needed }\end{array}$ & $\begin{array}{l}\text { May interact with each other, } \\
\text { but there is no evidence of } \\
\text { clinical concern }\end{array}$ \\
\hline $\mathrm{C}$ & $\begin{array}{l}\text { Monitor } \\
\text { therapy }\end{array}$ & $\begin{array}{l}\text { The benefits of concomitant } \\
\text { use of these two medications } \\
\text { usually outweigh the risks }\end{array}$ \\
\hline $\mathrm{D}$ & $\begin{array}{l}\text { Therapy } \\
\text { modification }\end{array}$ & $\begin{array}{l}\text { Assess whether the benefits } \\
\text { of concomitant therapy } \\
\text { outweigh the risks or not }\end{array}$ \\
\hline X & $\begin{array}{l}\text { Avoid } \\
\text { combination }\end{array}$ & $\begin{array}{l}\text { The risks associated with } \\
\text { concomitant use outweigh } \\
\text { the benefits }\end{array}$ \\
\hline
\end{tabular}

The diagnosis of the study patients was classified according to International Classification of Disease (ICD10) and drugs were classified according to Anatomical Therapeutic Chemical classification system (ATC). ${ }^{10,11}$

\section{Statistical analysis}

Results are expressed as percentage for age, gender, diagnosis, length of ICU stay, number of drugs prescribed, severity and risk involved.

\section{RESULTS}

A total of 35 patients were admitted in the ICU during the study period. Out of which 30 patients fulfilled the inclusion criteria and were included in the present study. Among the study population, 60\% (18) were males and $40 \%$ (12) were females (Figure 1). In the present study, the mean age of the population was 56.3 years (Figure 2). Average length of hospital stay was found to be 6.4 days.

The study population was exposed to a total of 330 medicines during the hospital stay with an average of 11.7 
drugs per patient. The major route of drug administration was parenteral that is, $61.5 \%$ (216) patients received parenteral medications while the rest $38.5 \%$ (135) patients received the drugs by other routes (Table 3 ).

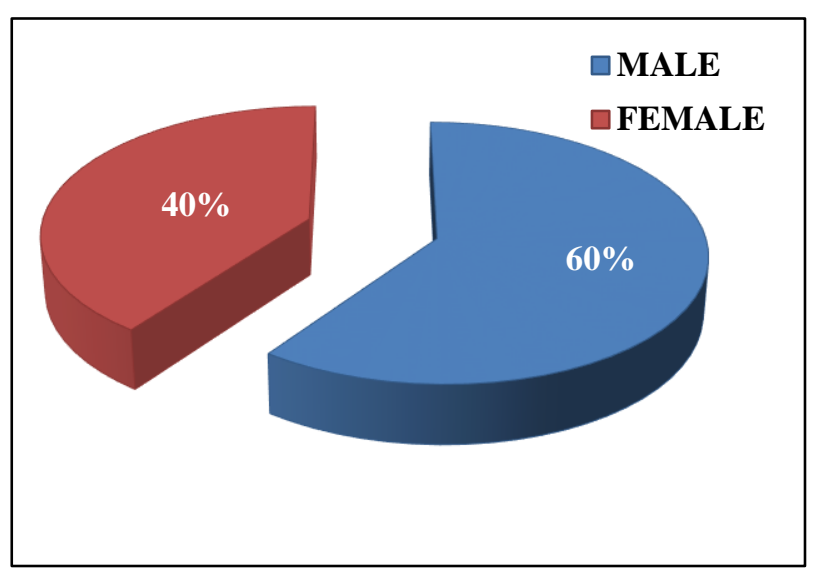

Figure 1: Gender of study population

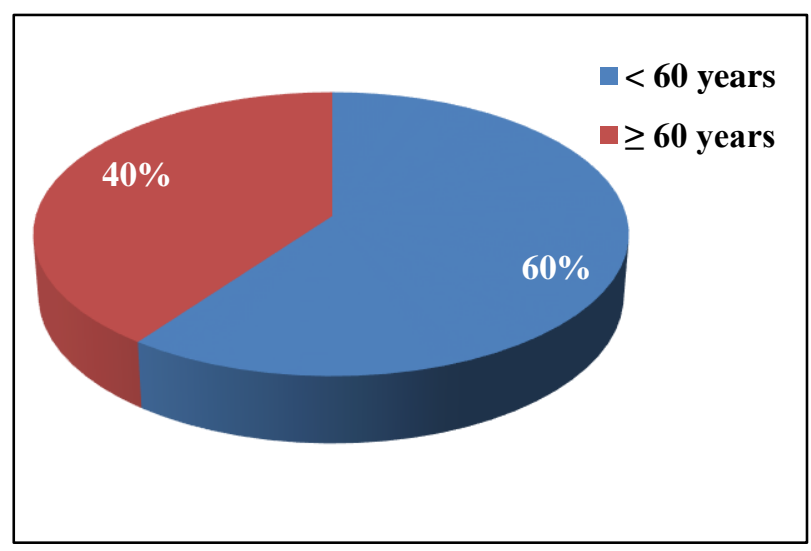

Figure 2: Age distribution in study population.

Table 3: Route of drug administration.

\begin{tabular}{|l|l|}
\hline $\begin{array}{l}\text { Route of drug } \\
\text { administration }\end{array}$ & $\begin{array}{l}\text { Number of drugs } \\
\text { (Percentage) }\end{array}$ \\
\hline Parenteral route & $216(61.5 \%)$ \\
\hline Other routes & $135(38.5 \%)$ \\
\hline
\end{tabular}

A total of $93.3 \%$ (28) of patients were exposed to atleast one potential drug-drug interactions. The total number of potential DDI observed in the study period was 273 , with an average of 9.75 potential DDI occurring per patient. According to Lexicomp drug interact android mobile application majority (63\%) of potential DDI were found to be moderate in their severity (Table 4).

Based on the risk category, about $67 \%$ of potential DDI belonged to type $\mathrm{C}$ risk (Figure 3 ). The maximum number of DDI observed for one patient was 19. The occurrence of DDIs is directly proportional to the no of drugs used (Figure 4).
Table 4: pDDI based on severity.

\begin{tabular}{|ll|}
\hline Category & Number of pDDI \\
\hline Major & $90(33 \%)$ \\
\hline Moderate & $171(63 \%)$ \\
\hline Minor & $12(4 \%)$ \\
\hline
\end{tabular}

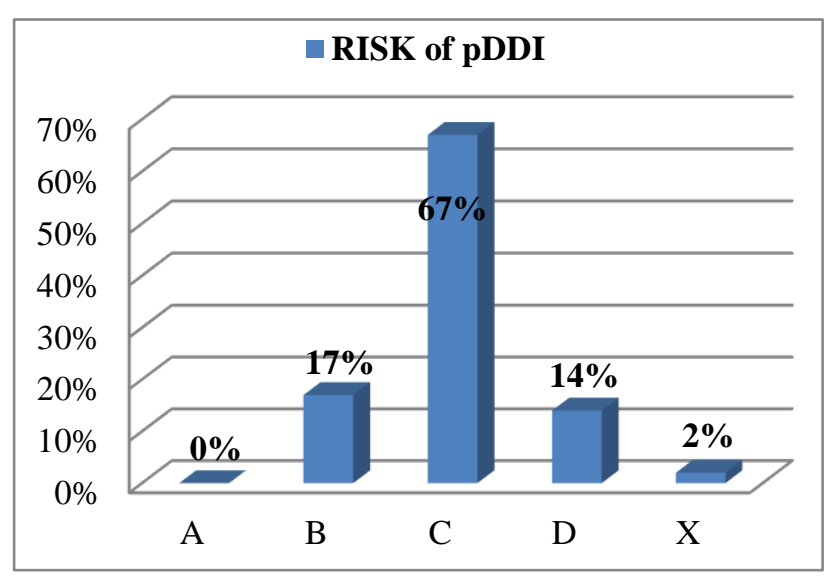

Figure 3: Percentage of pDDI based on the Risk scale.

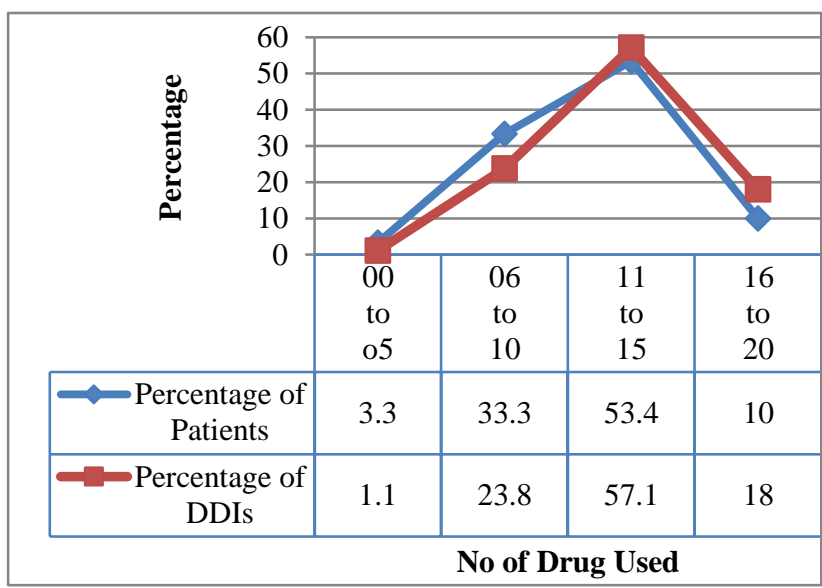

Figure 4: Drugs usage versus drug interactions and patient population.

According to Anatomical Therapeutic Classification (ATC) system, drugs in the cardiovascular system were the major category found to be interacting followed by alimentary tract and metabolism drugs. The most prevalent major and moderate DDI were those of anticoagulants and antiplatelet group (Table 5). The most common individual drug that caused pDDI was Clopidogrel followed by Aspirin and Heparin.

\section{DISCUSSION}

The present study assessed the prevalence of potential DDI in the ICU patients. $93.3 \%$ was the prevalence of pDDI in this study which is similar to a study conducted in the Northern India where the prevalence was $90.02 \%$ in MICU patients. ${ }^{4}$ Our study had male preponderance $(60 \%)$ which was similar to a study conducted by Manjeeta Gupta et al 
$(67.2 \%) .{ }^{13}$ Majority of the drugs were administered by parenteral route $(61.5 \%)$ which is similar to a study conducted by Lima et al $(62.3 \%) .{ }^{14}$ This is because most of the ICU patients are severely ill and require immediate drug effects.

Table 5: Ten most prevalent pDDI.

\begin{tabular}{|lllllll|}
\hline No. & pDDI & Risk & Severity & Reliability & Number & Percentage \\
\hline 1 & Clopidogrel + Atorvastatin & B & Moderate & Good & 21 & $7.69 \%$ \\
\hline 2 & Atorvastatin + Pantoprazole & C & Major & Poor & 18 & 6.59 \\
\hline 3 & Aspirin + Clopidogrel & C & Moderate & Fair & 15 & 5.49 \\
\hline 4 & Clopidogrel + Pantoprazole & D & Major & Fair & 15 & 5.49 \\
\hline 5 & Heparin + Aspirin & C & Major & Good & 15 & 5.49 \\
\hline 6 & Heparin + Clopidogrel & C & Moderate & Fair & 12 & 4.39 \\
\hline 7 & Streptokinase + Aspirin & C & Major & Fair & 6 & 2.19 \\
\hline 8 & Streptokinase + Clopidogrel & C & Major & Fair & 6 & 2.19 \\
\hline 9 & Isosorbide dinitrate + Metoprolol & C & Moderate & Fair & 6 & 2.19 \\
\hline 10 & Ringer Lactate + Heparin & C & Moderate & Fair & 6 & 2.19 \\
\hline
\end{tabular}

One of the major things to be considered while monitoring the pDDI is its severity. This study showed $63 \%$ of the observed pDDI were moderate in their severity. A study conducted by Sainul Abideen et al in 72 MICU patients found that $64.15 \%$ of DDI were moderate in their severity. ${ }^{4}$ A study by Manjeeta Gupta et al showed a similar result, about $60 \%$ of the observed pDDI were of moderate in nature. $^{13}$

According to the Lexicomp drug interact risk scale of pDDI, in this study, category $\mathrm{C}$ was the most common $67 \%$ which required monitoring of therapy, followed by Category B (17\%), D (14\%) and X (2\%). A study by Manjeeta Gupta et al reported a similar result, about $60.26 \%$ of pDDI belonged to category C while $14.41 \%$ and $3.93 \%$ belonged to category $\mathrm{D}$ and $\mathrm{X}$ respectively. ${ }^{13}$

Our study showed that occurrence of pDDI was directly proportional to the number of drugs administered. This is in accordance with the study conducted by Reis et al which concluded that there is association between pDDI and the number of drugs used. Another study by Abideen et al also reported a similar finding that there is a positive relation between number of drugs used and chances of interaction. ${ }^{4}$

This study showed similar results as compared to various other studies, that drugs in the cardiovascular system were the major category found to be interacting followed by alimentary tract and metabolism drugs. ${ }^{10,15-17}$ The most frequently interacting drug class involved in pDDIs may differ in different ICUs due to the co-morbid conditions of patients. $^{18}$

Interaction between an anticoagulant and antiplatelet was the most frequent in this study. Few other studies reported, aspirin and heparin or antithrombotic agents and antibacterial agents as the most commonly involved drugs/classes in causing DDIs in ICU patients. ${ }^{19,20}$
The study was mainly based on the information obtained from the Lexicomp drug interact Application. The patients were not monitored for the occurrence of DDI clinically and also the significant relationship of co-morbidities and length of stay in ICU was not evaluated. Sample size was too small and limited study duration without any intervention were other limitations of our study.

\section{ACKNOWLEDGEMENTS}

Authors would like to express their gratitude and thanks to Dr. Gajanan P Kulkarni, MD Pharmacology Associate professor and in-charge Head of Department of Pharmacology, Bidar Institute of Medical Sciences, Bidar for permitting us to undertake this research work.

\section{Funding: No funding sources \\ Conflict of interest: None declared}

Ethical approval: The study was approved by the Institutional Ethics Committee

\section{REFERENCES}

1. Hartshorn EA. Drug interaction: 1. General considerations. Ann Pharmacother. 2006;40(1):116-8.

2. Cremades J, Gonzalo M, Arrebola I. Relationship between drug interactions and drug-related negative clinical outcomes. Pharm Pract (Granada). 2009;7(1):34-9.

3. Moyen E, Camiré E, Stelfox HT. Clinical review: Medication errors in critical care. Critical Care. 2008;12(2):208-14.

4. Abideen S, Vivekanandan K, Mishra P. Assessment of prevalence of potential drug-drug interactions in medical intensive care unit of a tertiary care hospital in India. Asian Journal of Pharmaceutical and Clinical Research. 2015;8(1):125-30. 
5. Srivstava S. A complete textbook of Medical Pharmacology. 1st ed. Sirmour: Avichal publishing company; 2014.

6. Franceschi A, Tuccori M, Bocci G, Vannozzi F, Di Paolo A, Barbara C, et al. Drug therapeutic failures in emergency department patients. A university hospital experience. Pharmacol Res. 2004;49:85-91.

7. Johnell K, Klarin I. The relationship between number of drugs and potential drugdruginteractions in the elderly:A study of over 600,000 elderly patients from the Swedish Prescribed Drug Register. Drug Saf. 2007;30:911-8.

8. Pea F, Furlanut M. Pharmacokinetic aspects of treating infections in the intensive care unit. Focus on drug interaction Clin. Pharmacokinet. 2001;v.40,11:83368 .

9. Zagli G, Tarantini F, Bonizzoli M, Di Filippo A, Peris A, De Gaudio AR, et al. Altered pharmacology in the intensive care unit patient. Fundam Clin Pharmacol. 2008;22:493-501.

10. Kumar MA, Nizar A, Shailaja K, Jayasutha J, Ramasamy C. A study on prescribing pattern and potential drug-drug interactions in type 2 diabetes mellitus (inpatients) in a tertiary care teaching hospital. Der Pharmacia Lettre. 2011;3(4):13-9.

11. Ahmadizar F, Soleymani F, Abdollahi M. Study of drug interactions in prescriptions of general practitioners and specialists in Iran 2007-2009. Iran J Pharm Res. 2011;10(4):921-31.

12. Nabovati E, Arki HV, Taherzadeh Z, Hasibian MR, Hanna AA, Eslami S, et al. Drug-drug interactions in inpatient and outpatient settings in Iran: a systematic review of the literature. Daru. 2014;22(1):52.

13. Gupta M, Chincholkar A, Wagh R, Maheshwari N, Siddiqui W. A study of potential drug-drug interactions among critically ill patients at a tertiary care hospital. International Journal of Basic and Clinical Pharmacology. 2016;:1281-1285.
14. Lima R, Cassiani S. Potential drug interactions in intensive care patients at a teaching hospital. Revista Latino-Americana de Enfermagem. 2009;17(2):222-7.

15. Bleich GW, Bleich A, Chiamulera P, Sanches AC, Schneider DS, Teixeira JV, et al. Frequency of potential interactions between drugs in medical prescriptions in a city in southern Brazil. Sao Paulo Med J. 2009;127(4):206-10.

16. Teixeira JV, Crozatti MT, Santos CA, Lieber NS. Potential drug-drug interactions in prescriptions to patients over 45 years of age in primary care, southern Brazil. Public Lib Sci One. 2012;7(10):1-6.

17. Nobili A, Pasina L, Tettamanti M, Lucca U, Riva E, Marzona I. Potentially severe drug interactions in elderly outpatients: results of an observational study of an administrative prescription database. J Clinic Pharm Therap. 2009;34(4):377-86.

18. Oğlu MG, Küçükibrahimoğlu E, Karaalp A, Sarikaya Ö, Demirkapu M, Onat F, et al. Potential drug? drug interactions in a medical intensive care unit of a university hospital. Turkish Journal of Medical Sciences. 2016 Apr 19;46(3):812-9.

19. Smithburger PL, Kane-Gill SL, Seybert AL. Drugdrug interactions in the medical intensive care unit: an assessment of frequency, severity and the medications involved. Int JPharm Pract. 2012;20:402-8.

20. Askari M, Eslami S, Louws M, Wierenga PC, Dongelmans DA, Kuiper RA, et al. Frequency and nature of drug-drug interactions in the intensive care unit. Pharmacoepidemiol Drug Saf. 2013;22:430-7.

Cite this article as: Singh S, Swetha K. A prospective observational study to evaluate potential drug-drug interactions in patients admitted in intensive care unit, at BRIMS tertiary care hospital in Bidar, India. Int J Basic Clin Pharmacol 2018;7:6559. 